\title{
Hippocampal $\alpha 4 \beta 2$ Nicotinic Acetylcholine Receptor Involvement in the Enhancing Effect of Acute Nicotine on Contextual Fear Conditioning
}

\author{
Jennifer A. Davis, ${ }^{\star}$ Justin W. Kenney, ${ }^{\star}$ and Thomas J. Gould \\ Department of Psychology, Neuroscience Program, Temple University, Philadelphia, Pennsylvania 19122
}

\begin{abstract}
Nicotine is known to enhance learning and memory in hippocampus-dependent tasks such as contextual fear conditioning. The present study was designed to directly examine whether the hippocampus plays a role in mediating this enhancement and which nicotinic acetylcholine receptor (nAChR) subtypes localized to the hippocampus are critical for enhanced learning. Contextual fear conditioning consisted of two white noise conditioned stimuli presentations, each coterminating with a $2 \mathrm{~s}, 0.57 \mathrm{~mA}$ footshock separated by a $120 \mathrm{~s}$ intertrial interval. Nicotine $(0.09,0.18$, and $0.35 \mu \mathrm{g}$ per side) was bilaterally infused into the dorsal hippocampus before training and testing. Infusions of nicotine into the dorsal hippocampus produced a dose-dependent enhancement of contextual fear conditioning. To determine which $\mathrm{nAChRs}$ are critical to the enhancing effect of nicotine, the preferential $\alpha 4 \beta 2 \mathrm{nAChR}$ antagonist, dihydro- $\beta$ erythroidine (DH $\beta \mathrm{E}$ ) (6.00 and $18.00 \mu \mathrm{g}$ per side), or the preferential $\alpha 7 \mathrm{nAChR}$ antagonist, methyllycaconitine (MLA) (13.50 and 27.00 $\mu \mathrm{g}$ per side), was bilaterally infused into the dorsal hippocampus before systemic injections of nicotine $(0.09 \mathrm{mg} / \mathrm{kg})$. $\mathrm{DH} \beta \mathrm{E}$ infusions dose-dependently blocked the enhancement of contextual fear conditioning by nicotine, whereas MLA infusions yielded an intermediate effect. In addition, neither $\mathrm{DH} \beta \mathrm{E}$ nor MLA had an effect on contextual fear conditioning in the absence of systemic nicotine. The present results suggest a critical role for $\alpha 4 \beta 2 \mathrm{nAChRs}$ in the dorsal hippocampus for mediating the enhancing effect of nicotine on contextual fear conditioning.
\end{abstract}

Key words: nicotine; hippocampus; nAChRs; addiction; learning; mouse

\section{Introduction}

Studies assessing the role of the hippocampus in contextual and cued fear conditioning have revealed that the brain region is necessary for the former but not the latter task (Phillips and Ledoux, 1992; Kim et al., 1993; Logue et al., 1997). Thus, data indicating that acute systemic nicotine enhances contextual fear conditioning and has no effect on cued fear conditioning (for review, see Gould, 2006) suggest that the effect of nicotine on contextual fear conditioning is mediated by nicotinic acetylcholine receptors (nAChRs) in the hippocampus and/or a connected structure. However, the role of hippocampal nAChRs in the effect of acute nicotine on learning and memory has not been demonstrated directly. Equivocal results from previous studies (Barros et al., 2004; Sharifzadeh et al., 2005) indicate that the action of nicotine at hippocampal nAChRs may be sufficient to enhance learning and memory. But, it is not known whether the action of nicotine

Received July 17, 2007; revised Aug. 22, 2007; accepted Aug. 22, 2007.

This work was supported by National Institute on Drug Abuse (NIDA) Grant DA017949 (T.J.G.), Temple University (T.J.G.), and National Cancer Institute-NIDA Transdisciplinary Tobacco Use Research Center Grant P5084718 (principal investigator, Dr. Caryn Lerman). J.A.D. was supported by a National Institutes of Health (NIH)-NIDA predoctora fellowship (DA021949), and J.W.K. was supported by NIH-NIDA Training Grant T32DA07237. We thank Dr. Michael Lewis, Warren Anderson, and Jessica Porter for their contributions to this work.

*J.A.D. and J.W.K. contributed equally to this work.

Correspondence should be addressed to Dr. Thomas J. Gould, Department of Psychology, Weiss Hall, Temple University, Philadelphia, PA 19122. E-mail: tgould@temple.edu.

D01:10.1523/JNEUROSCI.3242-07.2007

Copyright $\odot 2007$ Society for Neuroscience $\quad 0270-6474 / 07 / 2710870-08 \$ 15.00 / 0$ at hippocampal nAChRs is necessary for the enhancement of learning and memory.

Neuronal nAChRs are a family of pentameric ion channels that are located throughout the CNS and comprise either $\alpha$ ( $\alpha 2-$ $\alpha 10$ ) or a combination of $\alpha$ and $\beta(\beta 2-\beta 4)$ subunits (for review, see Decker et al., 1995; Jones et al., 1999). Although a large number of nAChR subtypes exist, $\alpha 4 \beta 2$ (this subtype may include additional subunits) and $\alpha 7 \mathrm{nAChRs}$ comprise the majority of brain nAChRs (Wada et al., 1988; Couturier et al., 1990; Flores et al., 1992; Séguéla et al., 1993; Perry et al., 2002). Both subtypes are found in the hippocampus, but the specific localization and density of the subtypes within the hippocampus differ (Alkondon and Albuquerque, 1993, 2001). In addition, functional characteristics of these $\mathrm{nAChR}$ subtypes including affinity for nicotine, rate of desensitization and subsequent recovery, and cation permeability differ (Alkondon and Albuquerque, 1993; Séguéla et al., 1993; Decker et al., 1995), suggesting that the subtypes may mediate different processes.

There is strong evidence for a high comorbidity between smoking and a variety of disorders that affect hippocampal function, such as schizophrenia (de Leon et al., 1995; Dalack and Meador-Woodruff, 1996). This increased smoking behavior may be an attempt to self-medicate via ingestion of the psychoactive compound nicotine (Simosky et al., 2002; Kumari and Postma, 2005). Therefore, it is important to identify the nAChR subtypes and neural substrates that are critically involved in the effects of 
nicotine on learning and memory. The studies reported here examine whether hippocampal $\alpha 4 \beta 2 \mathrm{nAChRs}$ and/or $\alpha 7 \mathrm{nAChRs}$ mediate the effect of acute systemic nicotine on contextual fear conditioning. Specifically, the studies first determined whether intrahippocampal infusions of nicotine would enhance contextual fear conditioning. Then, it was examined whether intrahippocampal infusions of either dihydro- $\beta$-erythroidine $(\mathrm{DH} \beta \mathrm{E}$; a high-affinity nAChR antagonist that preferentially binds $\alpha 4 \beta 2$ nAChRs) or methyllycaconitine (MLA; an $\alpha 7 \mathrm{nAChR}$ antagonist), would block the enhancing effect of acute nicotine on contextual fear conditioning. The results demonstrate the critical involvement of $\alpha 4 \beta 2 \mathrm{nAChRs}$ in the hippocampus in the enhancing effect of acute nicotine on contextual fear conditioning.

\section{Materials and Methods}

Subjects. Subjects were male C57BL/6J mice or male and female $\alpha 7$ nAChR knock-out (KO) mice and their wild-type (WT) littermates 8-12 weeks of age. $\alpha 7 \mathrm{nAChR}$ KO and WT mice were bred from mice heterozygous for the mutation and genotyped using PCR [for a detailed description of mouse line generation and genotyping reactions, see OrrUrtreger et al. (1997)]. Mice were group housed (two to four per cage) before surgery and singly housed after surgery with ad libitum access to food and water. Housing cages $(27.5 \times 19.5 \times 16.0 \mathrm{~cm})$ were constructed of clear polycarbonate on the sides and bottom. Cage tops were metal rods that held food and water above the cage at a level that was accessible to the mice. Bed-o' cobs 1/8 inch bedding (The Andersons, Maumee, $\mathrm{OH})$ covered the floor of each housing cage. Mice were maintained on a $12 \mathrm{~h}$ light/dark cycle (lights on 7:00 A.M.). Training and testing occurred during the light phase. The Temple University Institutional Animal Care and Use Committee approved all behavioral and surgical procedures.

Apparatus. Training and testing for contextual fear conditioning occurred in four identical conditioning chambers $(17.8 \times 19.0 \times 38.1 \mathrm{~cm})$ housed in sound-attenuating boxes (Med Associates, St. Albans, VT). Each chamber consisted of stainless steel side walls and Plexiglas walls in the front and back. The floor of each chamber comprised metal rods (1.6 $\mathrm{mm}$ diameter) spaced $0.6 \mathrm{~cm}$ apart and connected to a shock generator and scrambler (model ENV-414; Med Associates). Ventilation fans were mounted on the back of each box to provide air exchange and background noise $(69 \mathrm{~dB})$, and speakers were mounted on the left wall for acoustic stimuli presentation. Stimuli administration was controlled via a personal computer running MED-PC software.

Testing for cued fear conditioning took place in four altered chambers $(20.3 \times 22.9 \times 17.8 \mathrm{~cm})$ located in a different room and distinct from those for training. The chambers consisted of Plexiglas front and back walls, metal side walls, and grid floors covered by opaque white plastic. Speakers were mounted above the chambers for acoustic stimuli presentation, and sidewall mounted fans provided background noise and air exchange. Vanilla extract was added to paper towels, which were placed under each chamber, to further distinguish the chambers from those used for training.

Behavioral procedures. Freezing, defined as a lack of movement except for respiration (Blanchard and Blanchard, 1969), served as the dependent measure. Freezing was assessed using a time-sampling procedure in which mice were observed for $1 \mathrm{~s}$ every $10 \mathrm{~s}$ and scored as freezing or active. Data are presented as percentage of $10 \mathrm{~s}$ intervals mice spent freezing.

Mice were trained in contextual fear conditioning as described previously (Gould and Wehner, 1999). Mice were placed in the chambers, and baseline freezing was assessed for $120 \mathrm{~s}$. After baseline, two coterminating conditioned stimulus (CS) (30 s, $85 \mathrm{~dB}$ white noise)-unconditioned stimulus (US) ( $2 \mathrm{~s}, 0.57 \mathrm{~mA}$ footshocks) presentations were separated by a $120 \mathrm{~s}$ intertrial interval. The training session ended with a $30 \mathrm{~s}$ stimulusfree period. Twenty-four hours after training, mice were placed into the same context, and freezing behavior was assessed over $5 \mathrm{~min}$.

Observed differences in contextual fear learning may reflect alterations in nonassociative processes such as arousal, locomotor activity, or attentional processes rather than changes in hippocampus-dependent learn- ing. To assess this possibility, separate groups of mice were trained and tested in cued fear conditioning, a task that is not hippocampus dependent. A modified delay fear-conditioning training procedure was used (Gould et al., 2004) to reduce freezing in response to the CS to reduce the likelihood of ceiling effects.

Training in cued fear conditioning consisted of one CS ( $85 \mathrm{~dB}$ white noise, $15 \mathrm{~s})$-US (0.57 mA, $2 \mathrm{~s})$ pairing that followed a $120 \mathrm{~s}$ stimuli-free period during which baseline freezing was assessed. After the CS-US pairing, mice remained in the training chambers for an additional $30 \mathrm{~s}$. Testing for cued conditioning occurred in the altered chambers $24 \mathrm{~h}$ after training. Mice were placed in the chambers for $6 \mathrm{~min}$. Freezing in the absence of the CS was scored during the first $3 \mathrm{~min}$, and during the last 3 min, freezing to the CS was assessed. Chambers were cleaned with a $70 \%$ ethanol solution after all behavioral procedures.

Surgery. Mice were anesthetized using isoflurane gas (5\% induction, 2-3\% maintenance) and placed in a stereotaxic apparatus (David Kopf Instruments, Tujunga, CA). The scalp was incised and retracted to expose the skull. Lambda and bregma were aligned in the same horizontal plane, and two 21 gauge holes were drilled into the skull. Bilateral stainless steel guide cannulas (C232G, 22 gauge; Plastics One, Roanoke, VA) were inserted and fixed to the skull with dental cement. Dummy cannulas (C232DC; Plastics One) were inserted into the guide cannulas to prevent clogging before infusion. Coordinates determined using the atlas of Paxinos and Franklin (2001) were as follows: posterior to bregma, $-1.7 \mathrm{~mm}$; mediolateral, $\pm 1.5 \mathrm{~mm}$; ventral to skull surface, $-0.76,-2.3$, and -3.3 $\mathrm{mm}$ for above, into, and below the dorsal hippocampus, respectively. To minimize postoperative pain, Buprenex $(0.03 \mathrm{mg} / \mathrm{kg})$ or Ketoprofen $(2.0$ $\mathrm{mg} / \mathrm{kg}$ ) was administered subcutaneously after surgery. Animals were allowed at least $5 \mathrm{~d}$ to recover before behavioral procedures began.

Drugs and infusion. All drugs were purchased from Sigma (St. Louis, $\mathrm{MO}$ ). Nicotine hydrogen tartrate salt [reported as freebase: $0.09 \mathrm{mg} / \mathrm{kg}$, i.p., or $0.09,0.18$, and $0.35 \mu \mathrm{g} / 0.50 \mu \mathrm{l}$ infusion per side based on Barros et al. (2004) and Quagazzal et al. (1999)], MLA [13.50 and 27.00 $\mu \mathrm{g} / 0.50$ $\mu \mathrm{l}$ based on Levin et al. (2002)], and DH $\beta \mathrm{E}$ [6.00 and $18.00 \mu \mathrm{g} / 0.50 \mu \mathrm{l}$ infusion per side based on Levin et al. (2002)] were dissolved in physiological saline. For experiments that required systemic administration of nicotine, the drug was administered intraperitoneally at an injection volume of $0.01 \mathrm{ml} / \mathrm{g}$ body weight $2-4 \mathrm{~min}$ before training and testing.

For direct infusions, mice were gently restrained and dummy cannulas were removed and replaced with 22 gauge infusion cannulas. Drugs were infused at a rate of $0.50 \mu \mathrm{l} / \mathrm{min}$ and at an injection volume of $0.50 \mu \mathrm{l}$ per side. Infusion cannulas were attached to polyethylene tubing (PE50; Plastics One), which was attached to a $10 \mu \mathrm{l}$ Hamilton (Reno, NV) syringe. Drug administration was controlled by a microinfusion pump (KDS 100; KD Scientific, New Hope, PA). Injection cannulas were left in place for 1 min after infusion to allow drug to diffuse away from the cannula tip. Nicotine was infused immediately before training and testing, and MLA or $\mathrm{DH} \beta \mathrm{E}$ was infused $15 \mathrm{~min}$ before training and testing. Spread of infusion using this procedure has been previously estimated to be $\sim 1$ $\mathrm{mm}^{3}$ (Lewis and Gould, 2007).

Histology. Animals were killed by cervical dislocation, and brains were rapidly dissected and placed in a $10 \%$ formalin solution (Fisher Scientific, Pittsburgh, PA) for at least $24 \mathrm{~h}$. Coronal sections (60 $\mu \mathrm{m}$ thick, proximal to injection tracks) were sliced at $-18^{\circ} \mathrm{C}$ using a cryostat and mounted on PLUS slides (Fisher Scientific). The sections were then stained with cresyl violet and coverslipped, and placements were determined using a light microscope. Data from animals with incorrect cannula placements were excluded from statistical analysis $(<10 \%)$.

Statistical analysis. ANOVAs were performed on percentage freezing data for experiments with three or more groups. Levene's tests were performed to determine whether the variances were equal across groups for each dependent variable. In situations in which variances were equal, Tukey's honestly significant difference analyses were performed to examine pairwise differences in percentage freezing data. If variances were unequal, Games-Howell post hoc tests were used. Independent-samples $t$ tests were performed on percentage freezing data for experiments with two groups. Analyses were performed with SPSS (Chicago, IL) version 11.0 software. 


\section{Results}

Intrahippocampal nicotine dose-

dependently enhances contextual

fear conditioning

To directly test whether the action of nicotine at hippocampal nAChRs is sufficient to enhance learning and memory, the effects of bilateral hippocampal infusions of saline or nicotine $(0.09,0.18$, or $0.35 \mu \mathrm{g}$ per side; $n=9-11$ ) on contextual fear conditioning were examined (Fig. 1A). A one-way ANOVA revealed that there were no effects of treatment on baseline freezing $(p>0.05)$, suggesting that there were no differences among the groups in general arousal and freezing behavior. There was an effect of treatment on contextual fear conditioning $\left(F_{(1,37)}=3.31 ; p<0.05\right)$. Follow-up Games-Howell comparisons revealed that mice treated with the highest dose of nicotine $(0.35 \mu \mathrm{g}$ per side) froze significantly more during testing than mice that received saline $(p<0.05)$. Mice treated with the lowest $(0.09 \mu \mathrm{g}$ per side) and the middle ( 0.18 $\mu \mathrm{g}$ per side) dose of nicotine demonstrated levels of contextual fear conditioning that were not different from levels of freezing demonstrated by mice treated with saline or the highest dose $(0.35 \mu \mathrm{g}$ per side) of nicotine ( $p>0.05$ for all comparisons). Thus, intrahippocampal nicotine dosedependently enhances contextual fear conditioning.

The enhancement of contextual fear conditioning by intrahippocampal nicotine may reflect effects of the drug in regions above and/or below the dorsal hippocampus. To assess this possibility, two additional experiments were conducted. Saline or nicotine $(0.35 \mu \mathrm{g}$ per side) was infused above the hippocampus in the first experiment $(n=6-7)$ (Fig. $1 B)$, and saline or nicotine $(0.35 \mu$ g per side) was infused below the dorsal hippocampus in the second experiment $(n=7-9)$ (Fig. 1B). Independent-samples $t$ tests revealed that nicotine-treated mice demonstrated levels of baseline freezing (data not shown) and contextual freezing that were similar to saline-treated mice when nicotine was infused either above or below the hippocampus ( $p>0.05$ for all comparisons). These data suggest that nAChRs in the hippocampus and not nAChRs in neighboring structures are involved in the enhancing effect of nicotine on contextual fear conditioning.

There are at least two possible interpretations of the data indicating that intrahippocampal nicotine dose-dependently enhances contextual fear conditioning: (1) nicotine acts at nAChRs in the hippocampus to enhance learning and memory processes that are involved in contextual fear conditioning; or (2) nicotine acts at nAChRs in the hippocampus to alter nonassociative processes such as attention, arousal, and/or locomotor activity. If the second interpretation is correct, then intrahippocampal nicotine administration should produce comparable effects on other similar tasks that may not critically depend on the hippocampus. To assess this possibility, the effect of intrahippocampal nicotine on delay cued fear conditioning was examined. Because previous research indicates that mice demonstrate ceiling levels of freezing
C

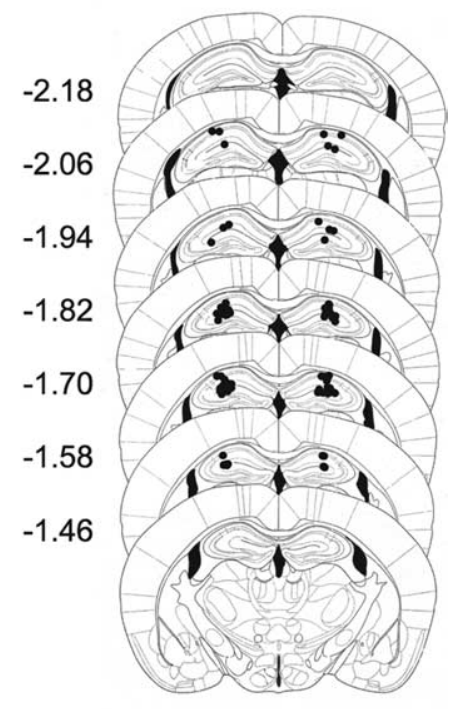

Figure 1. The effect of nicotine infused into, above, and below the dorsal hippocampus on contextual fear conditioning. $\boldsymbol{A}$, Mice received saline or nicotine $(0.09,0.18$, or $0.35 \mu \mathrm{g}$ per side) before training and testing in contextual fear conditioning. Mice that infusion tracts for all mice in the intrahippocampal nicotine experiment. Numbers represent distance in millimeters posterior to

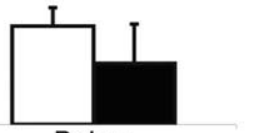

Below

in response to the CS after training with two CS-US pairings (Gould et al., 2004), mice receiving intrahippocampal saline or nicotine $(0.35 \mu \mathrm{g}$ per side) were trained using one pairing of the CS ( $15 \mathrm{~s})$ with the US $(n=7)$. Testing for freezing in response to the altered context and for freezing in response to the CS occurred $24 \mathrm{~h}$ after training (freezing in response to the CS: saline, $57.1 \pm 4.5 \%$; $0.35 \mu \mathrm{g}$ of nicotine, $55.6 \pm 4.1 \%$ ). Independentsamples $t$ tests revealed that there were no differences between mice treated with nicotine and mice treated with saline in pre-CS freezing $(p>0.05)$ or freezing in response to the CS $(p>0.05)$. These data suggest that the enhancing effect of intrahippocampal nicotine on contextual fear conditioning is attributable to enhanced learning and memory rather than changes in nonassociative processes.

Intrahippocampal $\mathrm{DH} \beta \mathrm{E}$, but not MLA, dose-dependently blocks the enhancing effect of systemic nicotine on contextual fear conditioning

The results thus far suggest that acute nicotine infused into the dorsal hippocampus is sufficient to enhance contextual fear conditioning. However, systemic nicotine may act at nAChRs in the hippocampus, other brain regions, or in both the hippocampus and other brain regions to enhance learning. Therefore, the next step was to determine whether activation of nAChRs in the dorsal hippocampus is necessary for the enhancement of contextual fear conditioning by nicotine and to determine which receptor subtypes are involved. To this end, $\mathrm{DH} \beta \mathrm{E}$ or MLA was infused into the dorsal hippocampus before the administration of systemic 
nicotine before contextual fear conditioning. Under these conditions, only the nAChRs in the hippocampus that are blocked by either of the antagonists would be insensitive to the action of nicotine.

To examine the effects of blocking $\mathrm{DH} \beta \mathrm{E}$-sensitive nAChRs in the hippocampus, mice received systemic injections of either saline or nicotine $(0.09 \mathrm{mg} / \mathrm{kg})$ and bilateral intrahippocampal infusions of saline or $\mathrm{DH} \beta \mathrm{E}$ (6.00 $\mu \mathrm{g}$ or $18.00 \mu \mathrm{g}$ per side) before training and testing for freezing in response to the context (Fig. $2 A)$. Four experimental conditions were used $(n=12-13)$ : (1) intrahippocampal saline and systemic saline; (2) intrahippocampal saline and systemic nicotine; (3) intrahippocampal $\mathrm{DH} \beta \mathrm{E}$ (6.00 $\mu \mathrm{g}$ per side) and systemic nicotine; and (4) intrahippocampal DH $\beta$ E (18.00 $\mu$ g per side) and systemic nicotine. A one-way ANOVA revealed that there was an effect of treatment on contextual fear conditioning $\left(F_{(3,49)}=4.02 ; p<0.05\right)$. Consistent with previous research (for review, see Gould, 2006), Tukey-adjusted post hoc comparisons revealed that mice that received intrahippocampal saline and systemic nicotine demonstrated significantly higher levels of contextual fear conditioning than mice that received intrahippocampal saline and systemic saline $(p<0.05)$. In addition, the enhancing effect of systemic nicotine on contextual fear conditioning was blocked by intrahippocampal infusions of $18.00 \mu \mathrm{g}$ per side $(p<0.05)$ but not by $6.00 \mu \mathrm{g}$ per side of $\mathrm{DH} \beta \mathrm{E}(p>0.05)$. These results suggest that hippocampal

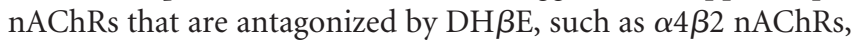
are necessary for the enhancing effect of acute systemic nicotine on contextual fear conditioning and that nicotine is not acting in another brain area in parallel with the hippocampus to enhance contextual fear conditioning. There was no effect of treatment on baseline freezing $(p>0.05)$, suggesting that differences between groups were not attributable to alterations in arousal or locomotor activity.

The effect of $\mathrm{DH} \beta \mathrm{E}$ administration alone was also examined $(n=9-10)$ (Fig. 2B). Mice received either intrahippocampal saline and systemic saline or intrahippocampal DH $\beta \mathrm{E}(18.00 \mu \mathrm{g}$ per side) and systemic saline. Independent-samples $t$ tests revealed that there was no effect of $\mathrm{DH} \beta \mathrm{E}$ administration on baseline freezing $(p>0.05)$ or freezing in response to the training context $(p>0.05)$. Thus, consistent with results from previous studies that used systemic antagonist administration (Davis and Gould, 2006), nAChRs that are antagonized by $\mathrm{DH} \beta \mathrm{E}$ are not necessary for contextual fear conditioning.

In an effort to determine whether $\mathrm{nAChR}$ subtypes besides those that are blocked by $\mathrm{DH} \beta \mathrm{E}$ are involved in the enhancement of contextual fear conditioning by nicotine, the effect of intrahippocampal MLA, an $\alpha 7 \mathrm{nAChR}$ antagonist, on the enhancement of contextual fear conditioning by nicotine was examined (Fig. $3 A)$. Four experimental groups were used $(n=10-12)$ : (1) intrahippocampal saline and systemic saline; (2) intrahippocampal saline and systemic nicotine; (3) intrahippocampal MLA (13.50 $\mu \mathrm{g}$ per side) and systemic nicotine; and (4) intrahippocampal MLA (27.00 $\mu \mathrm{g}$ per side) and systemic nicotine. A one-way ANOVA revealed an effect of drug treatment on contextual fear conditioning $\left(F_{(3,39)}=3.20 ; p<0.05\right)$ and no effect on baseline freezing $(p>0.05)$. Follow-up Tukey-adjusted comparisons revealed that mice that received intrahippocampal saline and systemic nicotine froze significantly more than mice that received intrahippocampal saline and systemic saline $(p<0.05)$. No other comparisons were significant $(p>0.05$ for all comparisons). However, intrahippocampal MLA administration was associated with an intermediate effect; mice that received MLA and
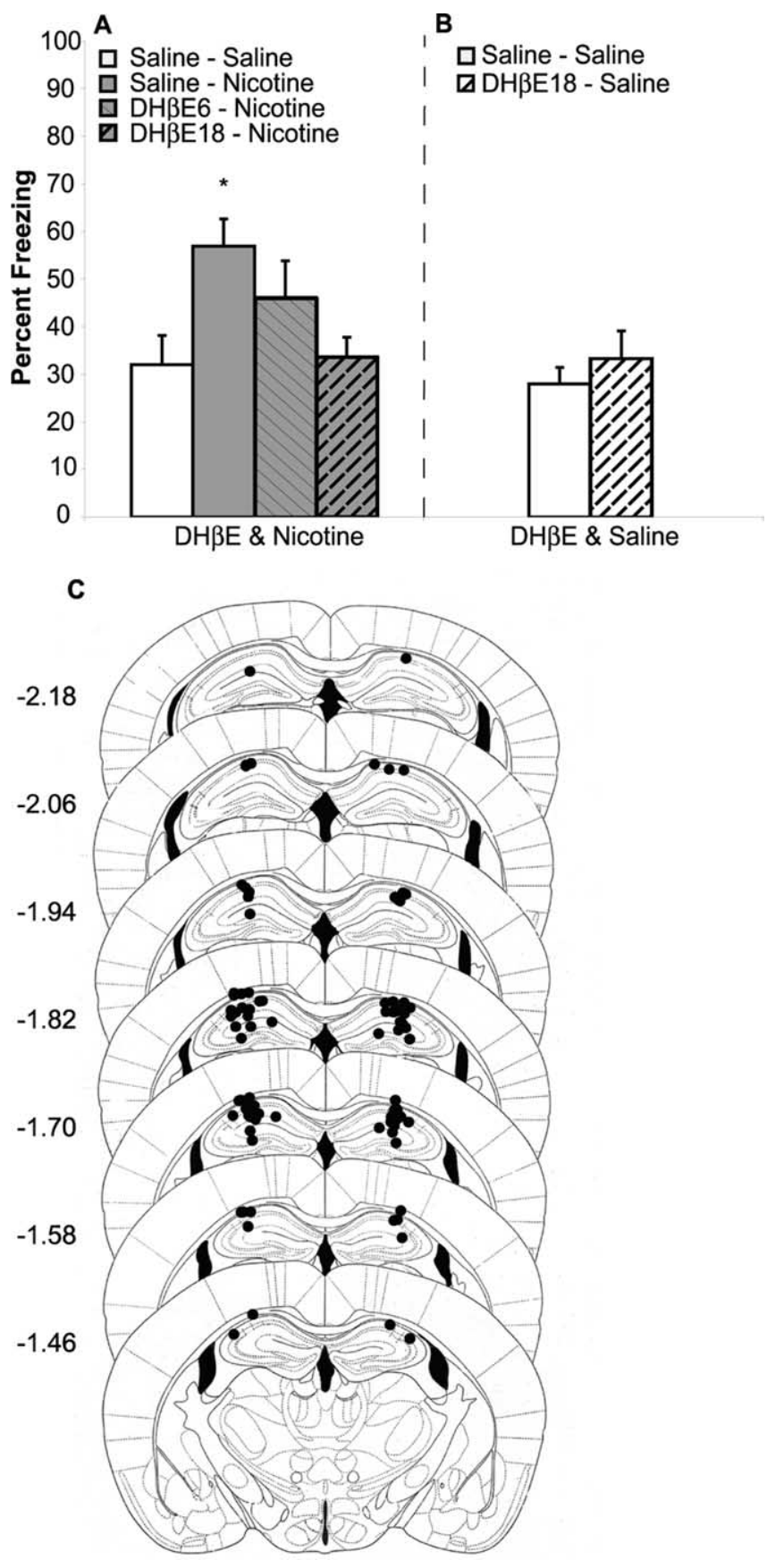

Figure 2. The effect of intrahippocampal $\mathrm{DH} \beta \mathrm{E}$ on the enhancement of contextual fear conditioning by systemic nicotine. $\boldsymbol{A}$, Mice received either systemic saline or nicotine $(0.09$ $\mathrm{mg} / \mathrm{kg}$ ) and intrahippocampal saline or $\mathrm{DH} \beta \mathrm{E}$ ( 6.00 or $18.00 \mu \mathrm{g}$ per side). Mice that received intrahippocampal saline and systemic nicotine froze significantly more in response to the context than mice that received intrahippocampal saline and systemic saline and intrahippocampal $\mathrm{DH} \beta \mathrm{E}$ (18.00 $\mu \mathrm{g}$ per side) and systemic nicotine. ${ }^{*} p<0.05$, compared with the intrahippocampal saline-systemic saline and intrahippocampal $\mathrm{DH} \beta \mathrm{E}(18.00 \mu \mathrm{g}$ per side)-systemic nicotine groups. $\boldsymbol{B}$, In the absence of nicotine, $\mathrm{DH} \beta \mathrm{E}$ (18.00 $\mu \mathrm{g}$ per side) has no effect on contextual fear conditioning. Error bars represent SEM. $\boldsymbol{C}$, Dots represent the tip of infusion tracts for mice in the $\mathrm{DH} \beta \mathrm{E}$ and nicotine experiment from $\boldsymbol{A}$. Numbers represent distance in millimeters posterior to bregma. Pictures were modified from Paxinos and Franklin (2001).

nicotine were not significantly different from the saline control group.

The effect of intrahippocampal MLA administration alone on contextual fear conditioning was also assessed (Fig. 3B) using the following groups ( $n=10)$ : (1) intrahippocampal saline and sys- 

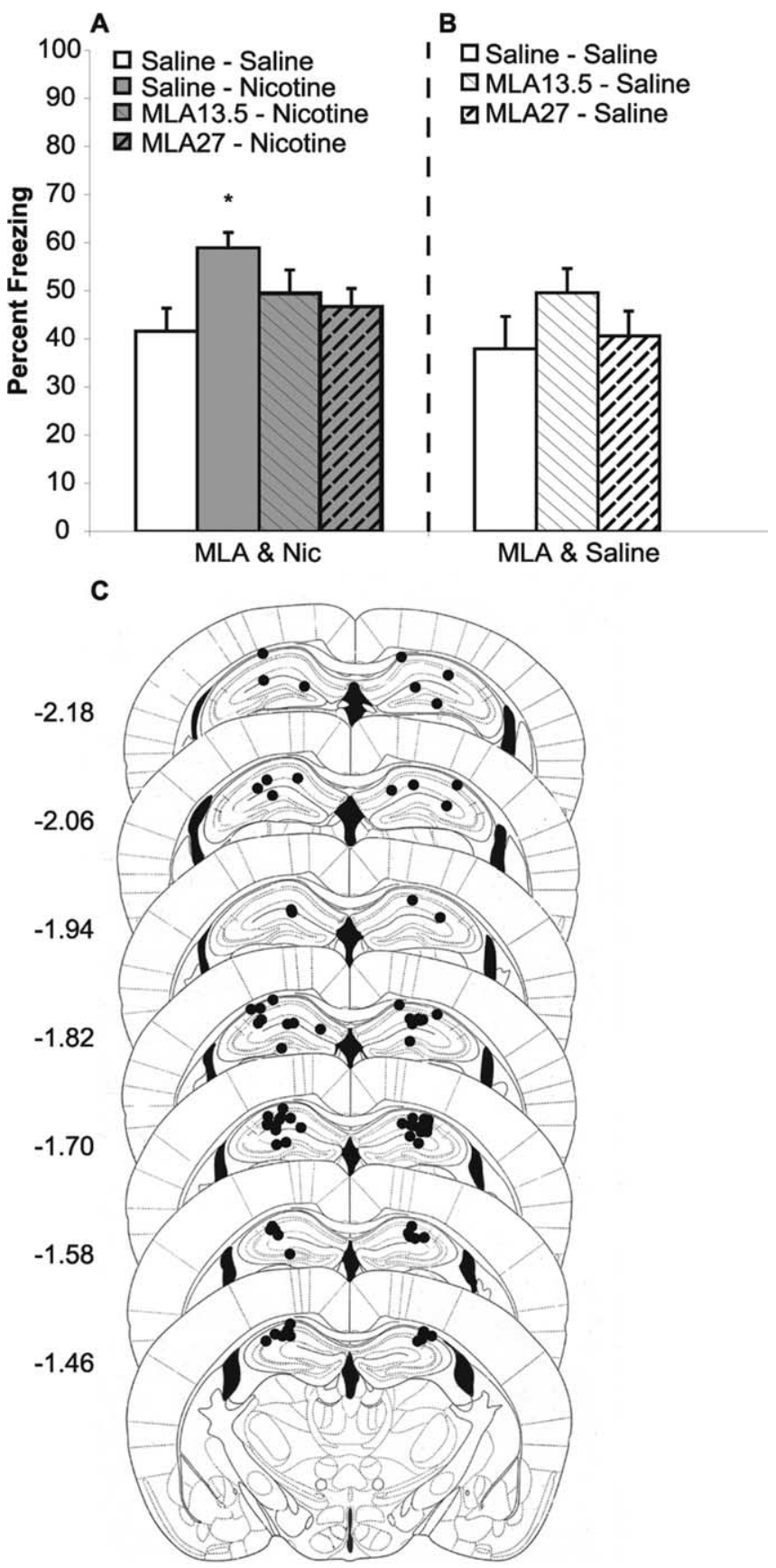

Figure 3. The effect of intrahippocampal MLA on the enhancement of contextual fear conditioning by systemic nicotine. $A$, Mice received either systemic saline or nicotine $(0.09 \mathrm{mg} / \mathrm{kg})$ and intrahippocampal saline or MLA (13.50 or $27.00 \mu \mathrm{g}$ per side). Mice that received intrahippocampal saline and systemic nicotine froze significantly more in response to the context than mice that received intrahippocampal saline and systemic saline. ${ }^{*} p<0.05$, compared with the intrahippocampal saline-systemic saline group. $\boldsymbol{B}$, MLA (13.50 or $27.00 \mu \mathrm{g}$ per side) had no effect on contextual fear conditioning in the absence of nicotine. Error bars represent SEM. $C$, Dots represent the tip of infusion tracts for mice in the MLA and nicotine experiment from $\boldsymbol{A}$. Numbers represent distance in millimeters posterior to bregma. Pictures were modified from Paxinos and Franklin (2001).

temic saline; (2) intrahippocampal MLA (13.50 $\mu$ g per side) and systemic saline; and (3) intrahippocampal MLA (27.00 $\mu \mathrm{g}$ per side) and systemic saline. A one-way ANOVA revealed no effect of treatment on contextual fear conditioning ( $p>0.05)$ or baseline freezing ( $p>0.05$ ). This result suggests that hippocampal $\alpha 7$ $\mathrm{nAChRs}$ are not involved in contextual fear conditioning.
Intrahippocampal MLA has the same effect on the enhancement of contextual fear conditioning by nicotine in $\alpha 7 \mathrm{nAChR}$ KO and WT mice

There are two potential interpretations of the results from the MLA hippocampal infusion experiment. One possibility is that the doses of MLA used may not have been large enough to produce a significant effect, and full attenuation of the enhancement of contextual fear conditioning may have occurred with a higher dose of the drug. However, this interpretation is unlikely given previous studies indicating that nicotine enhances contextual fear conditioning in mice that lack $\alpha 7 \mathrm{nAChRs} \mathrm{(Wehner} \mathrm{et} \mathrm{al.,}$ 2004; Davis and Gould, 2007). A second interpretation is that MLA attenuated the effect of systemic nicotine on contextual fear conditioning by antagonizing receptors other than $\alpha 7 \mathrm{nAChRs}$. To evaluate this possibility, a follow-up experiment using $\alpha 7$ $\mathrm{nAChR}$ KO and WT mice was performed. MLA or saline was infused into the dorsal hippocampi of $\alpha 7 \mathrm{nAChR} \mathrm{KO}$ and WT mice that were administered systemic saline or nicotine (Fig. 4). Thus, the following treatment groups existed for both $\mathrm{KO}$ and WT mice ( $n=13-14)$ : (1) intrahippocampal saline and systemic saline; (2) intrahippocampal saline and systemic nicotine; and (3) intrahippocampal MLA (27.00 $\mu \mathrm{g}$ per side) and systemic nicotine.

Initial analyses revealed that there were no significant differences between male and female mice ( $p>0.05$ for all comparisons). Therefore, data from male and female mice were combined for analyses. A $3 \times 2$ (treatment $\times$ genotype) ANOVA revealed no significant interaction $(p>0.05)$ but a main effect of treatment $\left(F_{(2,68)}=5.69 ; p<0.05\right)$ on contextual fear conditioning. Follow-up Tukey-adjusted comparisons within genotype revealed that mice receiving intrahippocampal saline and systemic nicotine demonstrated higher levels of freezing in response to the context than mice receiving intrahippocampal saline and systemic saline $(p<0.05)$, demonstrating that nicotine will enhance contextual fear conditioning in $\alpha 7 \mathrm{KO}$ mice. No other pairwise comparisons were significant $(p>0.05)$. However, intrahippocampal MLA administration yielded an intermediate effect similar to the effect described in the earlier experiment; WT and $\mathrm{KO}$ mice that received systemic nicotine and intrahippocampal MLA demonstrated levels of freezing to the context that were not different from those of the saline control group. Thus, the intermediate effect of MLA on the enhancement of contextual fear conditioning by systemic nicotine in C57BL/6 mice is likely caused by MLA acting at receptors other than $\alpha 7 \mathrm{nAChRs}$.

\section{Discussion}

The major findings of the present studies are as follows: (1) intrahippocampal nicotine dose-dependently enhances contextual fear conditioning; (2) the demonstrated enhancement of contextual fear conditioning is not attributable to the action of nicotine in cortical regions above or thalamic regions below the hippocampus; (3) intrahippocampal nicotine enhanced associative learning (i.e., the context-US association) rather than nonassociative processes because cued feared conditioning was unaffected by intrahippocampal nicotine administration; and (4) nicotine acts at $\mathrm{DH} \beta \mathrm{E}$-sensitive hippocampal nAChRs to produce its effects on contextual fear conditioning; antagonism of hippocampal $\mathrm{DH} \beta \mathrm{E}$-sensitive $\mathrm{nAChR}$ blocked the enhancing effect of acute systemic nicotine on contextual fear conditioning. These data strongly suggest that the action of nicotine at $\mathrm{DH} \beta \mathrm{E}$ sensitive hippocampal nAChRs is necessary and not simply sufficient for the nicotine-associated enhancement of this task.

A previous study that used systemic coadministration of 

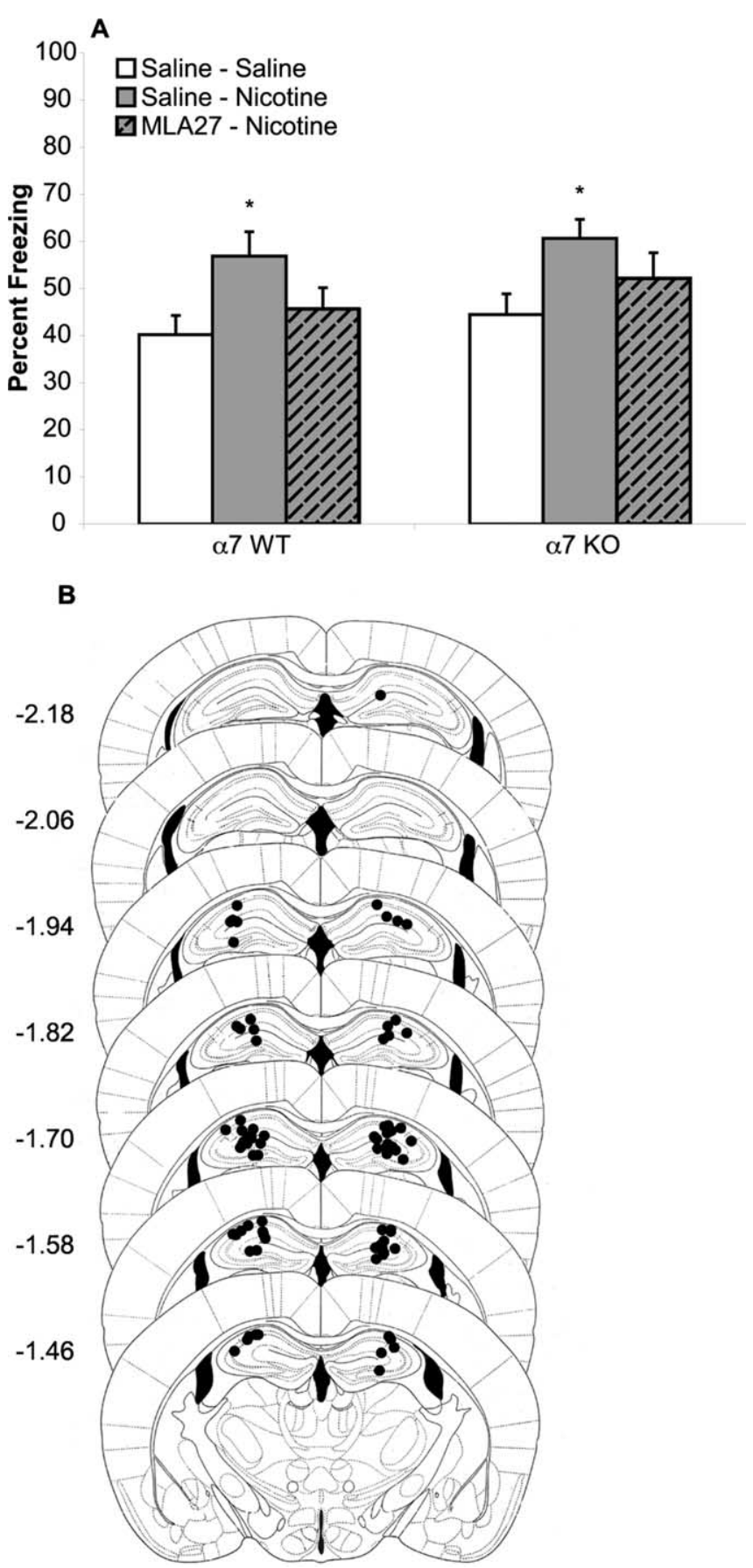

Figure 4. The effect of intrahippocampal MLA on the enhancement of contextual fear conditioning by systemic nicotine in $\alpha 7 \mathrm{nAChR}$ KO and WT mice. $A$, In both K0 and WT mice, systemic nicotine enhanced contextual fear conditioning. Intrahippocampal MLA (27.00 $\mu \mathrm{g}$ per side) had the same effect in both KO and WT mice on the ability of nicotine to enhance contextual fear conditioning. ${ }^{*} p<0.05$, compared with the intrahippocampal saline-systemic saline group. Error bars represent SEM. B, Dots represent the tip of infusion tracts for KO mice. Numbers represent distance in millimeters posterior to bregma. Pictures were modified from Paxinos and Franklin (2001).

$\mathrm{DH} \beta \mathrm{E}$ and nicotine suggested a role for $\mathrm{nAChRs}$ that are antagonized by $\mathrm{DH} \beta \mathrm{E}$ in the effects of acute nicotine on contextual fear conditioning (Davis and Gould, 2006); systemic administration of $\mathrm{DH} \beta \mathrm{E}$ dose-dependently blocked the enhancing effect of acute systemic nicotine on contextual fear conditioning. However, the brain region(s) through which nicotine produces its effect on the task could not be identified from the results of the study, because systemic administration of nicotine and $\mathrm{DH} \beta \mathrm{E}$ will, by definition, result in the action of the drugs throughout the central and peripheral nervous systems. Thus, the results of the present research significantly extend the findings of Davis and Gould (2006) and the findings from previous studies indicating that nicotine enhances hippocampus-dependent learning and memory (Buccafusco et al., 1996; Levin et al., 1997; Gould and Wehner, 1999; Barros et al., 2004; Sharifzadeh et al., 2005) by directly demonstrating that $\mathrm{DH} \beta \mathrm{E}$-sensitive nAChRs in the hippocampus are critical for the enhancing effect of the drug.

$\mathrm{DH} \beta \mathrm{E}$ antagonizes $\mathrm{nAChR}$ subtypes, including $\alpha 4 \beta 2, \alpha 4 \beta 4$, $\alpha 3 \beta 2, \alpha 2 \beta 2$, and $\alpha 2 \beta 4 \mathrm{nAChRs}$, that bind nicotine with high affinity (Harvey et al., 1996; Khiroug et al., 2004). Thus, the present results identify a group of nAChR subtypes that could be necessary for the effect of acute nicotine on contextual fear conditioning. Two lines of evidence suggest that $\alpha 4 \beta 2 \mathrm{nAChRs}$ may be the critical nAChR subtype through which acute nicotine produces its effects on contextual fear conditioning. First, $\alpha 4 \beta 2$ nAChRs are not only the most sensitive subtype to DH $\beta \mathrm{E}$ (Harvey et al., 1996; Khiroug et al., 2004), but they are also among the most prominent neuronal nAChRs, accounting for $\sim 90 \%$ of nAChRs that bind nicotine with high affinity in the brain (Flores et al., 1992; Picciotto et al., 1995). Consistent with these data, $\alpha 4 \beta 2$ nAChRs are densely located in the hippocampus (for review, see Picciotto et al., 2001). Second, data from Wehner et al. (2004) and Davis and Gould (2007) indicate that nicotine fails to enhance contextual fear conditioning in $\beta 2 \mathrm{nAChR}$ subunit $\mathrm{KO}$ mice. Such data suggest that $\beta 2$ subunit-containing nAChRs, such as $\alpha 4 \beta 2$ nAChRs, are critical for the enhancing effect of acute nicotine on hippocampus-dependent forms of fear conditioning.

Nicotine both activates and desensitizes nAChRs (Decker et al., 1995; Jones et al., 1999). Thus, acute systemic nicotine may enhance contextual fear conditioning via activation, desensitization, or activation and subsequent desensitization of $\alpha 4 \beta 2$ $\mathrm{nAChRs.} \mathrm{However,} \mathrm{if} \mathrm{desensitization} \mathrm{of} \alpha 4 \beta 2 \mathrm{nAChRs}$ is critical for the effect of acute systemic nicotine on contextual fear conditioning, then it would be expected that functional inactivation of these receptors via intrahippocampal $\mathrm{DH} \beta \mathrm{E}$ administration would enhance contextual fear conditioning. This result was not seen. Thus, the present results support a necessary role for either $\alpha 4 \beta 2 \mathrm{nAChR}$ activation or $\alpha 4 \beta 2 \mathrm{nAChR}$ activation, followed by desensitization in the effect of acute systemic nicotine on contextual fear conditioning.

In contrast to the role $\alpha 4 \beta 2 \mathrm{nAChRs}$ seem to play in the enhancement of contextual fear conditioning by acute nicotine, $\alpha 7$ nAChRs do not seem to be critical to the effect despite their dense localization in the hippocampus (Alkondon and Albuquerque, 1993; Séguéla et al., 1993; Dominguez del Toro et al., 1994). In agreement with previous work (Paylor et al., 1998; Wehner et al., 2004; Davis and Gould, 2007), the present study found that $\alpha 7$ nAChR KO mice demonstrated normal contextual fear conditioning and enhancement of contextual fear conditioning by acute nicotine. Possible developmental compensatory alterations resulting from deletion of the $\alpha 7$ gene could limit the interpretability of these results. However, these data, along with the MLA results, suggest that $\alpha 7 \mathrm{nAChRs}$ are not necessary for the enhancing effect of nicotine on learning and memory.

The results indicating that MLA infusions nonsignificantly reduce the enhancement of contextual fear conditioning by nicotine in $\alpha 7 \mathrm{nAChR}$ KO mice suggest that at doses commonly used in infusion experiments, MLA may not be as selective for $\alpha 7$ $\mathrm{nAChRs}$ as is assumed. Additional support for this contention 
has come from studies indicating that MLA binds to a population of non- $\alpha 7$ nAChRs (Mogg et al., 2002), and the effects of MLA on nicotine-evoked $\mathrm{Ca}^{2+}$ influx (Ridley et al., 2002) and dopamine release from synaptosomes (Mogg et al., 2002) differ from those of the classic $\alpha 7 \mathrm{nAChR}$ antagonist, $\alpha$-bungarotoxin. Furthermore, Klink et al. (2001) found that MLA inhibited dopaminergic release from neuronal slices obtained from $\alpha 7 \mathrm{nAChR} \mathrm{KO}$ mice. Indeed, MLA has been found to bind to $\alpha 6$-containing nAChRs (Mogg et al., 2002), and at higher concentrations, $\alpha 3$ - and $\alpha 4$ containing receptors (Drasdo et al., 1992; Palma et al., 1996). The more selective $\alpha$-bungarotoxin was not used because of its irreversible binding characteristics and its convulsant and locomotor reduction properties (Kempsill and Pratt, 2000). Thus, the nonsignificant MLA-associated reduction of the enhancing effect of nicotine on contextual fear conditioning seen in the present studies is most likely attributable to the action of MLA at non- $\alpha 7$ nAChRs.

Differential involvement of the $\alpha 4 \beta 2$ and the $\alpha 7 \mathrm{nAChRs} \mathrm{may}$ reflect their divergence in functional characteristics and cellular localization. $\alpha 7 \mathrm{nAChRs}$ exhibit low affinity for nicotine and desensitize rapidly after activation by the drug, whereas $\alpha 4 \beta 2$ $\mathrm{nAChRs}$ exhibit high affinity for nicotine and desensitize more slowly after activation (Alkondon and Albuquerque, 1993). Thus, the activation of $\alpha 4 \beta 2$ and $\alpha 7 \mathrm{nAChRs}$ are associated with longlasting (tonic) and short-lasting (phasic) synaptic responses, respectively (Alkondon et al., 1999). Furthermore, $\alpha 7$ nAChRs localized to pyramidal cells can influence synaptic plasticity (Ji et al., 2001), whereas both $\alpha 7$ and $\alpha 4 \beta 2$ nAChRs appreciably contribute to the modulation of hippocampal pyramidal cell activity and plasticity by innervating GABAergic interneurons (Alkondon et al., 1998, 1999; Ji and Dani, 2000; Alkondon and Albuquerque, 2001). Therefore, the data from the present study suggest that nicotine may have its effect on modulating contextual fear conditioning by altering the tonic activation of hippocampal interneurons as opposed to acting directly at hippocampal pyramidal cells.

There are at least two possible broad mechanisms downstream from $\alpha 4 \beta 2 \mathrm{nAChRs}$ by which nicotine may act to enhance contextual fear conditioning. First, activation of $\alpha 4 \beta 2 \mathrm{nAChRs}$ may increase the strength of signaling pathways that are normally involved in contextual fear conditioning. For example, the extracellular-regulated kinases (ERKs) have been implicated in contextual fear conditioning (Sweatt, 2001), and nicotine is known to increase phosphorylation of ERK in PC12 h cells by activation of non- $\alpha 7$ nAChRs (Nakayama et al., 2001) and in mouse neuroblastoma N1E-115 cells (Tomizawa and Casida, 2002). Thus, nicotine-associated increases in ERK activation may increase the strength of synaptic alterations that may underlie learning. In support, Raybuck and Gould (2007) demonstrated that decreasing ERK activity blocked the enhancing effect of nicotine on contextual fear conditioning. Alternatively, nicotine may activate a pathway that is not usually recruited during contextual fear learning. Activation of such a pathway may act in parallel with those usually activated to enhance learning. Determining the downstream mechanisms by which activation of hippocampal $\alpha 4 \beta 2 \mathrm{nAChRs}$ effects learning and memory is an important next step in understanding how nicotine alters cognition.

\section{References}

Alkondon M, Albuquerque EX (1993) Diversity of nicotinic acetylcholine receptors in rat hippocampal neurons. I. Pharmacological and functional evidence for distinct structural subtypes. J Pharmacol Exp Ther 265:1455-1473.
Alkondon M, Albuquerque EX (2001) Nicotinic acetylcholine receptor alpha7 and alpha4beta2 subtypes differentially control GABAergic input to CA1 neurons in rat hippocampus. J Neurophysiol 86:3043-3055.

Alkondon M, Pereira EFR, Albuquerque EX (1998) $\alpha$-Bungarotoxin-and methyllycaconitine-sensitive nicotinic receptors mediate fast synaptic transmission in interneurons of rat hippocampal slices. Brain Res 810:257-263.

Alkondon M, Pereira EFR, Eisenberg HM, Albuquerque EX (1999) Choline and selective antagonists identify two subtypes of nicotinic acetylcholine receptors that modulate GABA release from CA1 interneurons in rat hippocampal slices. J Neurosci 19:2693-2705.

Barros DM, Ramirez MR, Dos Reis EA, Izquierdo I (2004) Participation of hippocampal nicotinic receptors in acquisition, consolidation and retrieval of memory for one trial inhibitory avoidance in rats. Neuroscience 126:651-656.

Blanchard RJ, Blanchard DC (1969) Passive and active reactions to feareliciting stimuli. J Comp Physiol Psychol 68:129-135.

Buccafusco JJ, Prendergast MA, Terry AV, Jackson WJ (1996) Cognitive effects of nicotinic cholinergic receptor agonists in nonhuman primates. Drug Dev Res 38:196-203.

Couturier S, Bertrand D, Matter J, Hernandez M, Bertrand S, Millar N, Valera S, Barkas T, Ballivet M (1990) A neuronal nicotinic acetylcholine receptor subunit $(\alpha 7)$ is developmentally regulated and forms a homooligomeric channel blocked by $\alpha$-BTX. Neuron 5:847-856.

Dalack GW, Meador-Woodruff JH (1996) Smoking, smoking withdrawal and schizophrenia: case reports and a review of the literature. Schizophr Res 22:133-141.

Davis JA, Gould TJ (2006) The Effects of DHBE and MLA on nicotineinduced enhancement of contextual fear conditioning. Psychopharmacology 184:345-352.

Davis JA, Gould TJ (2007) $\beta 2$ subunit-containing nicotinic receptors mediate the enhancing effect of nicotine on trace cued fear conditioning in C57BL/6 mice. Psychopharmacology 190:343-352.

Decker MW, Brioni JD, Bannon AW, Arneric SP (1995) Diversity of neuronal nicotinic acetylcholine receptors: lessons from behavior and implications for CNS therapeutics. Life Sci 56:545-570.

de Leon J, Dadvand M, Canuso C, White AO, Stanilla JK, Simpson GM (1995) Schizophrenia and smoking: an epidemiological survey in a state hospital. Am J Psychiatry 152:453-455.

Dominguez del Toro E, Juiz JM, Peng X, Lindstrom J, Criado M (1994) Immunocytochemical localization of the alpha 7 subunit of the nicotinic acetylcholine receptor in the rat central nervous system. J Comp Neurol 349:325-342.

Drasdo A, Caulfield M, Bertrand D, Bertrand S, Wonnacott S (1992) Methyllycaconitine: a novel nicotinic antagonist. Mol Cell Neurosci 3:237-243.

Flores CM, Rogers SW, Pabreza LA, Wolfe BB, Kellar KJ (1992) A subtype of nicotinic cholinergic receptor in rat brain is composed of $\alpha 4$ and $\beta 2$ subunits and is upregulated by chronic nicotine treatment. Mol Pharmacol 41:31-37.

Gould TJ (2006) Nicotine and hippocampus-dependent learning: implications for addiction. Mol Neurobiol 34:93-107.

Gould TJ, Wehner JM (1999) Nicotine enhancement of contextual fear conditioning. Behav Brain Res 102:31-39.

Gould TJ, Feiro O, Moore D (2004) Nicotine enhances trace cued fear conditioning but not delay cued fear conditioning in C57BL/6 mice. Behav Brain Res 155:167-173.

Harvey SC, Maddox FN, Luetje CW (1996) Multiple determents of dihydro- $\beta$-erythroidine sensitivity on rat neuronal nicotinic receptor $\alpha$ subunits. J Neurochem 67:1953-1959.

Ji D, Dani JA (2000) Inhibition and disinhibition of pyramidal neurons by activation of nicotinic receptors on hippocampal interneurons. J Neurophysiol 83:2682-2690.

Ji D, Lape R, Dani JA (2001) Timing and location of nicotinic activity enhances or depresses hippocampal synaptic plasticity. Neuron 31:131-141.

Jones S, Sudweeks S, Yakel JL (1999) Nicotinic receptors in the brain: correlating physiology with function. Trends Neurosci 22:555-561.

Kempsill FEJ, Pratt JA (2000) Mecamylamine but not the $\alpha 7$ receptor antagonist $\alpha$-bungarotoxin blocks sensitization to the locomoter stimulant effects of nicotine. Br J Pharmacol 131:997-1003.

Khiroug SS, Khiroug L, Yakel JL (2004) Rat nicotinic acetylcholine receptor $\alpha 2 \beta 2$ channels: comparison of functional properties with $\alpha 4 \beta 2$ channels in Xenopus oocytes. Neuroscience 124:817-822. 
Kim JJ, Rison RA, Fanselow MS (1993) Effects of amygdala, hippocampus, and periaqueductal gray lesions on short- and long-term contextual fear. Behav Neurosci 107:1093-1098.

Klink R, de Kerchove d'Exaerde A, Zoli M, Changeux JP (2001) Molecular and physiological diversity of nicotinic acetylcholine receptors in midbrain dopaminergic nuclei. J Neurosci 21:1452-1463.

Kumari V, Postma P (2005) Nicotine use in schizophrenia: the selfmedication hypothesis. Neurosci Biobehav Rev 29:21-34.

Levin ED, Kaplan S, Boardman A (1997) Acute nicotine interactions with nicotinic and muscarinic agonists: working memory and reference memory effects in the 16-arm radial maze. Behav Pharmacol 8:236-242.

Levin ED, Bradley A, Addy N, Siqurani N (2002) Hippocampal alpha 7 and alpha 4 beta 2 nicotinic receptors and working memory. Neuroscience 109:757-765.

Lewis MC, Gould TJ (2007) Reversible inactivation of the entorhinal cortex disrupts the establishment and expression of latent inhibition of cued fear conditioning in C57BL/6 mice. Hippocampus 17:462-470.

Logue SF, Paylor R, Wehner JM (1997) Hippocampal lesions cause learning deficits in inbred mice in the Morris water maze and conditioned-fear task. Behav Neurosci 111:104-113.

Mogg AJ, Whiteaker P, McIntosh JM, Marks M, Collins AC, Wonnacott S (2002) Methyllycaconitine is a potent antagonist of $\alpha$-conotoxin-MIIsensitive presynaptic nicotinic acetylcholine receptors in rat striatum. J Pharmacol Exp Ther 302:197-204.

Nakayama H, Numakawa T, Ikeuchi T, Hatanaka H (2001) Nicotineinduced phosphorylation of extracellular signal-regulated protein kinase and CREB in PC12h cells. J Neurochem 79:489-498.

Orr-Urtreger A, Göldner FM, Saeki M, Lorenzo I, Goldberg L, De Biasi M, Dani JA, Patrick JW, Beaudet AL (1997) Mice deficient in the $\alpha 7$ neuronal nicotinic acetylcholine receptor lack $\alpha$-bungarotoxin binding sites and hippocampal fast nicotinic currents. J Neurosci 17:9165-9171.

Palma E, Bertrand S, Binzoni T, Bertrand D (1996) Neuronal nicotinic alpha 7 receptor expressed in Xenopus oocytes presents five putative binding sites for methyllycaconitine. J Physiol (Lond) 491:151-161.

Paxinos G, Franklin KBJ (2001) The mouse brain in stereotaxic coordinates. San Diego: Academic.

Paylor R, Nguyen M, Crawley JN, Patrick J, Beaudet A, Orr-Urtreger A (1998) $\alpha 7$ nicotinic receptor subunits are not necessary for hippocampal-dependent learning or sensorimotor gaing: a behavioral characterization of Acra7-deficient mice. Learn Mem 5:302-316.

Perry DC, Xiao Y, Nguyen HN, Musachio JL, Davila-Garcia MI, Kellar KJ (2002) Measuring nicotinic receptors with characteristics of $\alpha 4 \beta 2, \alpha 3 \beta 2$, and $\alpha 3 \beta 4$ subtypes in rat tissues by autoradiography. J Neurochem $82: 468-481$.

Phillips RG, Ledoux JE (1992) Differential contribution of amygdala and hippocampus to cued and contextual fear conditioning. Behav Neurosci 106:274-285.

Picciotto MR, Zoli M, Lena C, Bessis A, Lallemand Y, LeNovere N, Vincent P, Pich EM, Brulet P, Changeux JP (1995) Abnormal avoidance learning in mice lacking functional high-affinity nicotine receptor in the brain. Nature 374:65-67.

Picciotto MR, Caldarone BJ, Brunzell DH, Zachariou V, Stevens TR, King SL (2001) Neuronal nicotinic acetylcholine receptor subunit knockout mice: physiological and behavioral phenotypes and possible clinical implications. Pharmacol Ther 92:89-108.

Quagazzal AM, Kenny PJ, File SE (1999) Modulation of behaviour on trials 1 and 2 in the elevated plus-maze test of anxiety after systemic and hippocampal administration of nicotine. Psychopharmacology 144:54-60.

Raybuck JD, Gould TJ (2007) Extracellular signal-regulated kinase involvement in the enhancement of contextual fear conditioning by nicotine. Behav Neurosci, in press.

Ridley DL, Pakkanen J, Wonnacott S (2002) Effects of chronic drug treatments on increases in intracellular calcium mediated by nicotinic acetylcholine receptors in SH-SY5Y cells. Br J Pharmacol 135:1051-1059.

Séguéla P, Wadiche J, Dineley-Miller K, Dani JA, Patrick JW (1993) Molecular cloning, functional properties, and distribution of rat brain $\alpha 7$ : a nicotinic cation channel highly permeable to calcium. J Neurosci 13:596-604.

Sharifzadeh M, Tavasoli M, Naghdi N, Ghanbari A, Amini M, Roghani (2005) Post-training intrahippocampal infusion of nicotine prevents spatial memory retention deficits induced by the cyclo-oxygenase-2specific inhibitor celecoxib in rats. J Neurochem 95:1078-1090.

Simosky JK, Stevens KE, Freedman R (2002) Nicotinic agonists and psychosis. Curr Drug Targets CNS Neurol Disord 1:149-162.

Sweatt JD (2001) The neuronal MAP kinase cascade: a biochemical signal integration system subserving plasticity and memory. J Neurochem 76:1-10.

Tomizawa M, Casida JE (2002) Desnitro-imidacloprid activates the extracellular signal-regulated kinase cascade via the nicotinic receptor and intracellular calcium mobilization in N1E-115 cells. Toxicol Appl Pharmacol 184:180-186.

Wada E, Wada K, Boulter J, Deneris E, Heinemann S, Patrick J, Swanson LW (1988) Distribution of alpha2, alpha3, alpha4, and beta2 neuronal nicotinic receptor subunit mRNAs in the central nervous system: a hybridization histochemical study in the rat. J Comp Neurol 284:314-335.

Wehner JM, Keller JJ, Keller AB, Picciotto MR, Paylor R, Booker TK, Beaudet A, Heinemann SF, Balogh SA (2004) Role of neuronal nicotinic receptors in the effects of nicotine and ethanol on contextual fear conditioning. Neuroscience 129:11-24. 